\title{
Ink Solvent Dependence of the Ionomer Distribution in the Catalyst Layer of a PEMFC
}

\author{
Alin Orfanidi, $\circledast^{1, z}$ Philipp J. Rheinländer, ${ }^{1, *}$ Nicole Schulte, ${ }^{1,2, *}$ \\ and Hubert A. Gasteiger ${ }^{1, * *}$
}

${ }^{1}$ Chair of Technical Electrochemistry, Department of Chemistry and Catalysis Research Center, Technische Universität
München, D-85748 Garching, Germany
${ }^{2}$ Department of Applied Sciences and Mechatronics, Munich University of Applied Sciences, D-80335 Munich,
Germany

This study examines the effect of ink composition on the ionomer distribution in the catalyst layer of membrane electrode assemblies (MEA) prepared by decal transfer. We combine both structural and electrochemical characterization techniques to investigate the influence of the ionomer distribution on MEA performance determined by $50 \mathrm{~cm}^{2}$ active area single-cell proton exchange membrane (PEM) fuel cell measurements. Cathodic catalyst layers were prepared from inks with different alcohols (1-propanol or 2-propanol) and varying water content (16-65 wt $\% \mathrm{H}_{2} \mathrm{O}$ ). The $\mathrm{H}_{2} /$ air performance of cathode catalyst layers prepared from the different inks with $700 \mathrm{EW}$ ionomer differed drastically, particularly under wet operating conditions, whereby the best performance was obtained for an ink based on $16 \mathrm{wt} \% \mathrm{H}_{2} \mathrm{O}$ in 1-propanol. This was successfully correlated with the observation of ionomer patches at the cathode electrode surface (i.e., the surface facing the diffusion medium) determined by scanning electron microscopy (SEM), with $\mathrm{N}_{2}$ adsorption analysis of the electrodes using a QSDFT model, and with dynamic light scattering data of ionomer/solvent mixtures. No correlation could be obtained between $\mathrm{H}_{2}$ /air performance and the proton conductivity of the cathodes obtained by electrochemical impedance spectroscopy, and a model to rationalize this behavior will be proposed.

(C) The Author(s) 2018. Published by ECS. This is an open access article distributed under the terms of the Creative Commons Attribution 4.0 License (CC BY, http://creativecommons.org/licenses/by/4.0/), which permits unrestricted reuse of the work in any medium, provided the original work is properly cited. [DOI: 10.1149/2.1251814jes]

(cc) BY

Manuscript submitted September 4, 2018; revised manuscript received October 31, 2018. Published November 15, 2018.

One of the biggest challenges in proton exchange membrane fuel cell (PEMFC) research is the fabrication of membrane electrode assemblies (MEAs) with a maximized $\mathrm{H}_{2}$ /air performance at high current densities, which we believe largely depends on the homogeneity of the ionomer distribution particularly within the cathode electrode. Over the past decade, there have been numerous studies focusing on the optimization of the catalyst layer and the MEA assembly. The uniformity of the ionomer distribution on the catalyst surface depends on the manufacturing procedure of the catalyst layer, ${ }^{1-4}$ and recent high-resolution transmission electron microscopy studies showed that the ionomer coverage on a typical catalyst carbon-support may be rather inhomogeneous. ${ }^{5}$ One of the most commonly used lab-scale methods for MEA fabrication from catalyst inks (a dispersion of catalyst, ionomer, and suitable solvents) is the so-called decal transfer method, which was first introduced by Wilson and Gottesfeld. ${ }^{6,7}$ This method comprises coating a catalyst ink onto a suitable substrate (e.g., a PTFE-based substrate film), followed by a transfer of the dried coating onto the membrane by hot-pressing.

It has been demonstrated that the catalyst ink properties and composition are critical in order to obtain a good catalyst layer. ${ }^{8-10}$ Typically, a catalyst ink contains the catalyst (e.g., platinum supported on a high-structure carbon black), a perfluorosulfonic acid (PFSA) ionomer, and a dispersing solvent, usually a mixture of water and aliphatic alcohols (ethanol, 1-propanol, etc.). The catalyst inks are mixed, using a roller-mixer, an ultrasonic disperser, or other mixing devices, seeking to thoroughly disperse the catalyst aggregates and to obtain optimum contact between the ionomer and the catalyst particles. The solid content of the catalyst ink and the type/composition of the dispersing solvent control the viscosity ${ }^{11}$ and homogeneity of the ink, ${ }^{12}$ and thus the size of catalyst aggregates in the catalyst layer (CL). Besides these properties, the type of solvent also significantly influences the structure/size of the dispersed ionomer in the ink, ${ }^{13}$ which will likely affect the distribution of the ionomer on the catalyst particle surface and within the catalyst layer, so that it should ultimately affect fuel cell performance. Nafion 1100-EW (equivalent weight) ionomer is the most studied ionomer in the literature, whereby the structure of primary aggregates (from rod-like to coils) and the

\footnotetext{
*Electrochemical Society Student Member
}

**Electrochemical Society Fellow.

${ }^{\mathrm{z}}$ E-mail: orfanidi.alin@gmail.com size of the secondary aggregates in solvents with different dielectric constants as well as with differing water content has been thoroughly evaluated. ${ }^{14-16}$

Mainly driven by automotive PEMFC developers who strive for fuel cell operation at higher temperatures and lower RH (relative humidity) in combination with low Pt loaded electrodes, ${ }^{17-19}$ low$\mathrm{EW}\left(\mathrm{EW} \equiv g_{\text {polymer }} / \mathrm{mol}_{\mathrm{H}+}\right)$ ionomers are preferred for electrode manufacturing. ${ }^{1,20}$ Many studies have highlighted the advantage of low-EW ionomers on MEA performance. ${ }^{10,21-23}$ In our present study we investigate the behavior of a low-EW ionomer (700 EW) with respect to different ink compositions, providing a correlation between the hydrodynamic radii of the low-EW ionomer in different dispersing solvents with the ionomer distribution within the catalyst layer and with the performance of cathode catalyst layers manufactured via the decal transfer method. Specifically, we aim to shed more light on the effect of solvent type and water content in the catalyst ink on the resulting catalyst layer morphology when using a low-EW ionomer. We combine a variety of both structural and electrochemical characterization techniques to establish a correlation between the ionomer distribution within the cathode catalyst layer and MEA performance under both dry and wet operating conditions, as well as the effective proton conductivity in the catalyst layer.

\section{Experimental}

Membrane electrode assembly (MEA) preparation and cell assembly.-All $50 \mathrm{~cm}^{2}$ geo MEAs were fabricated using the decal transfer method. The catalyst inks were prepared by mixing a carbon-supported (graphitzed Ketjen black) catalyst with 46.9 wt\% platinum (referred to as $46.9 \mathrm{wt} \% \mathrm{Pt} / \mathrm{C}_{\mathrm{g}}$; from Tanaka Kikinzoku (TEC10EA50E)) with a low-EW PFSA (perfluorosulfonic acid) ionomer in a water-alcohol solution (700 EW from Asahi Kasei). The ionomer was kept in the acid form throughout the fabrication process of the catalyst inks. The ink's components were added in the following sequence into a $15 \mathrm{ml}$ HDPE bottle containing $16.5 \mathrm{~g}$ of $5 \mathrm{~mm}$ diameter $\mathrm{ZrO}_{2}$ beads: 1) catalyst, 2) water, 3) solvent, and, 4) ionomer dispersion. The investigated ionomer solvents were water/alcohol (1-propanol and 2-propanol) mixtures, whereby the water concentration was varied between 16-65 wt\%. The carbon content in the inks was fixed to $0.05 \mathrm{~g}_{\mathrm{C}} / \mathrm{ml}_{\text {ink }}$ in order to guarantee a satisfactory viscosity for the coating process. The inks were mixed using a 
roller-mill at $60 \mathrm{rpm}$ for $18 \mathrm{~h}$ at room temperature $\left(\sim 25^{\circ} \mathrm{C}\right)$ in order to obtain homogeneous catalyst inks. A total of 6 types of catalyst inks were prepared. Thereafter, the inks were coated onto virgin PTFE foil (thickness of $50 \mu \mathrm{m}$ ) using a Mayer rod coater (Erichsen). The coating speed was in all cases $10 \mathrm{~mm} / \mathrm{sec}$. The Mayer rod that was used produced a wet film thickness of $80 \mu \mathrm{m}$, which was left to dry at room temperature under a slight vacuum to facilitate the solvents evaporation. Once the electrode was visibly dry ( $\sim$ approximately after $3 \mathrm{~min}$ ), the decals were placed in an oven at $80^{\circ} \mathrm{C}$ for complete removal of solvents. It has to be noted that while a catalyst ink comprised of $65 \mathrm{wt} \% \mathrm{H}_{2} \mathrm{O}$ in 2-propanol was used to prepare decals, this particular ink composition resulted in such a poor ionomer distribution that the electrode could not be transferred onto the membrane during the hot pressing procedure, so that MEAs based on this ink could not be tested.

The platinum loading of the cathode electrodes was around $\sim 0.3 \mathrm{mg}_{\mathrm{Pt}} / \mathrm{cm}^{2}$ geo (see details in Table I), with an ionomer to carbon weight ratio (I/C) of 0.65 . The loading of the electrodes was determined by weighing the decals before and after the catalyst layer transfer. The same anodes were used for all measurements: $0.1 \mathrm{mg}_{\mathrm{Pt}} / \mathrm{cm}^{2}{ }_{\text {geo }}$ using the same catalyst $\left(46.9 \mathrm{wt} \% \mathrm{Pt} / \mathrm{C}_{\mathrm{g}}\right)$ with an $\mathrm{I} / \mathrm{C}$ ratio of 0.65 . MEAs with $50 \mathrm{~cm}^{2}$ geo active area were assembled by hot pressing a $15 \mu \mathrm{m}$ membrane (Asahi Kasei) between the two electrode decals at $155^{\circ} \mathrm{C}$ for $3 \mathrm{~min}$ with an applied force of $0.24 \mathrm{kN} / \mathrm{cm}^{2}$ active area. All inks and decals were manufactured twice to assure reproducibility. Accordingly, two inks were prepared independently for each cathode ink recipe, from which MEAs were prepared and measured; the error bars included in all figures correspond to the standard deviation between two independent measurements obtained from the two different inks or from two MEAs, each prepared from a different but nominally identical ink.

Fuel cell testing.-The electrochemical measurements were performed using a single-cell hardware purchased from Fuel Cell Technologies Inc., fitted with $50 \mathrm{~cm}^{2}$ geo active area graphite flow-fields ${ }^{24}$ (14 parallel channels with $0.5 \mathrm{~mm}$ wide lands/channels; made by Poco Graphite). The applied torque during cell assembly was $12 \mathrm{Nm}$ and the compression of the gas diffusion media (Freudenberg H14C7, with an uncompressed thickness of $\sim 170 \mu \mathrm{m}$ ) was set to $20 \%$ by using incompressible fiberglass-reinforced PTFE-gaskets with the appropriate thickness. Fuel cell tests were performed on an automated Greenlight Innovation fuel cell test station (type G60). All MEAs were conditioned before testing using the same voltage-controlled ramp-in procedure $\left(\mathrm{H}_{2} /\right.$ air flows of $1390 / 3320 \mathrm{nccm}$ at $80^{\circ} \mathrm{C}, 100 \%$ relative humidity, and $150 \mathrm{kPa}_{\text {abs,inlet }}$ ): $0.6 \mathrm{~V}$ for $45 \mathrm{~min}, 5 \mathrm{~min}$ at $\mathrm{OCV}$, and $10 \mathrm{~min}$ at $0.85 \mathrm{~V}$, this sequence was repeated 10 times, after which constant performance was reached. Stoichiometric-flow $\mathrm{H}_{2} /$ air $(\mathrm{s}=$ $1.5 / 2.0)$ and $\mathrm{H}_{2} / \mathrm{O}_{2}(\mathrm{~s}=2.0 / 9.5)$ polarization curves were recorded in current-control mode at $170 \mathrm{kPa}_{\text {abs }}$ inlet pressure, with both reactants humidified to the same relative humidity (RH). Here, $\mathrm{H}_{2} / \mathrm{O}_{2}$ curves were taken at $80^{\circ} \mathrm{C}$ and $100 \% \mathrm{RH}$, while two different conditions were applied for $\mathrm{H}_{2}$ /air curves: $60^{\circ} \mathrm{C}$ and $100 \% \mathrm{RH}$, and $80^{\circ} \mathrm{C}$ and $30 \% \mathrm{RH}$. Prior to recording a polarization curve from low to high current densities, MEAs were conditioned at $0.75 \mathrm{~V}$ for $15 \mathrm{~min}$; each current density point was held for $10 \mathrm{~min}$ and the resulting voltage was averaged over the final $30 \mathrm{~s}$. AC impedance spectra were collected at each current density to determine the respective high frequency resistance, using a Gamry Ref3000 potentiostat.

Electrochemical characterization.-The electrochemically active surface area (ECSA) of the cathode electrode was evaluated via cyclic voltammetry, averaging the $\mathrm{H}$-desorption and $\mathrm{H}$-adsorption charge and using a reference value of $210 \mu \mathrm{C} / \mathrm{cm}_{\mathrm{Pt}}{ }^{2}$. The counter/reference electrode was fed with $200 \mathrm{nccm}$ of fully humidified $5 \% \mathrm{H}_{2}$ in $\mathrm{N}_{2}$, while the working electrode was first flushed with dry $\mathrm{N}_{2}$, the flow of which was stopped during recording the CVs. The potential was cycled at $50 \mathrm{mV} / \mathrm{s}$ between 0.03 and $1.0 \mathrm{~V}$ (vs. the counter electrode) at $40^{\circ} \mathrm{C}$ and ambient pressure. The shorting resistance and the $\mathrm{H}_{2}$ cross- over currents were measured under $\mathrm{H}_{2} / \mathrm{N}_{2}$ at $170 \mathrm{kPa}_{\text {abs inlet }}, 80^{\circ} \mathrm{C}$, and $100 \% \mathrm{RH}$.

The proton conduction resistance in the cathode electrode was determined by AC impedance (using a Gamry Ref3000 potentiostat) under $\mathrm{H}_{2} / \mathrm{N}_{2}$ (anode/cathode) at $0.2 \mathrm{~V}$, following previous work ${ }^{25}$ (peak-to-peak perturbation of $3.5 \mathrm{mV}$ between $200 \mathrm{kHz}$ and $0.2 \mathrm{~Hz}$, with 20 points per decade). Three spectra were collected at each condition to verify reproducibility. Proton conduction resistances $\left(\mathrm{R}_{\mathrm{H}+\text {,cath }}\right)$ were determined at $100,70,50$, and $30 \% \mathrm{RH}$ at $80^{\circ} \mathrm{C}$ under differential flow conditions $\left(\mathrm{H}_{2} / \mathrm{N}_{2}\right.$ at $\left.2000 / 7500 \mathrm{nccm}\right)$, maintaining constant gas partial pressures (i.e., at cell pressures of 270, 255, 246, and $236 \mathrm{kPa}_{\mathrm{abs}}$, respectively). The obtained Nyquist plots were fitted to an extended transmission line model for a $\mathrm{N}_{2}$ working electrode (see the equivalent circuit shown in S1), using the fitting tool implemented in EC-Lab V10.40 (Bio-Logic Science Instruments). The effective proton resistance $R_{H+\text {,cath }}^{\text {eff }}$ (in units of $\Omega \mathrm{cm}^{2}$ ) was calculated by using Equation 1, taken from Liu et al. ${ }^{26}$ and was used to correct for the proton conduction resistance induced voltage loss. The proton resistivity $\rho_{\mathrm{H}+\text {,cath }}$ (in units of $\Omega \mathrm{cm}$ ) was calculated by dividing the proton resistance $\left(R_{\mathrm{H}+\text {,cath }}\right)$ by the cathode electrode thickness (calculated from the well-known packing density of Vulcan carbon based electrodes of $\left.\sim 28 \mu \mathrm{m} /\left(\mathrm{mg}_{\mathrm{C}} / \mathrm{cm}^{2}\right)^{27}\right)$.

$$
R_{H+, \text { cath }}^{e f f}=\frac{R_{\mathrm{H}+, \mathrm{cath}}}{3+\zeta}
$$

Microstructure of catalyst and catalyst layers. - The surface areas and pore structure of the catalyst powder and electrodes were evaluated by $\mathrm{N}_{2}$ physisorption at $77 \mathrm{~K}$ using a Quantachrome Autosorb-iQ instrument. All samples were degassed under vacuum at $90^{\circ} \mathrm{C}$ for $15 \mathrm{~h}$ prior to physisorption measurements. For the analysis of the electrode coatings, the catalyst layer was scratched off from the PTFE substrate and introduced into the instrument's sample tube. A pretreatment temperature of $90^{\circ} \mathrm{C}$ was chosen to preserve the integrity of the ionomer and was confirmed to be sufficient for the accuracy of measurement. Adsorption and desorption isotherms of all samples were recorded in the relative pressure range of $10^{-5} \leq\left(\mathrm{p} / \mathrm{p}_{\mathrm{o}}\right) \leq 0.995$, where $\mathrm{p}$ represents the gas pressure and $p_{o}$ the saturation pressure. This specific relative pressure range was chosen in order to ensure high resolution in the micro and mesopore region (supported by the use of a high-precision pressure transducer); to ensure high accuracy, the sample weight was adjusted to have a minimum absolute surface area of $>10 \mathrm{~m}^{2}$. The specific surface area and pore volume distribution were calculated by the Brunauer-Emmett-Teller (BET) method and by the quenched solid density functional theory (QSDFT) method, respectively (using the ASiQwin program). The adsorption branch was used for the BET surface area calculation using a multipoint fit (best fit within $\left.0.01 \leq\left(\mathrm{p} / \mathrm{p}_{\mathrm{o}}\right) \leq 0.25\right)$. In addition, a slit/cylindrical pore and adsorption QSDFT kernel was used for the characterization of the nanopore size distribution (small mesopores and micropores with $<30 \mathrm{~nm}$ ) of the carbons. It should be noted that QSDFT is more accurate than other theories or non-local density functional theory (NLDFT), as it takes into consideration the heterogeneity of the carbon surface and thus gives a more realistic estimate of the micro and mesopore contribution. ${ }^{28,29}$

Scanning electron microscopy (SEM).--Images with high contrast and high resolution, the distribution of the ionomer in macropores of the catalyst layer was evaluated by use of FE-SEM (JSM-7500F, JEOL, Japan) with a secondary electron detector. In order not to damage or alter the ionomer structure/morphology during image acquisition, the "gentle beam" mode was used with a low acceleration voltage of $0.5 \mathrm{kV}$. The imaging was performed at the back side of the decal, i.e., after hot pressing a decal against a PFSA membrane; thus, the images represent the electrode surface which would face the gas diffusion layers (GDLs) in an assembled cell. For the evaluation of the ionomer coverage across pores within the electrode structure, the sizes of these ionomer patches were measured manually using ImageJ. 
Table I. Cathode electrode Pt loadings $\left(\mathrm{L}_{\mathrm{Pt}}\right)$ and $\mathrm{I} / \mathrm{C}$ mass ratios, their electrochemically active surface area (ECSA) determined by cyclic voltammetry, and their ORR mass activity at $0.9 \mathrm{~V}, 80^{\circ} \mathrm{C}$, and $100 \% \mathrm{RH}$ at the experimentally used $\mathrm{H}_{2}$ and $\mathrm{O}_{2}$ partial pressures of $123 \mathrm{kPa} \mathrm{a}_{\mathrm{abs}}$,inlet $\left(i_{m}\right)$ as well as extrapolated to $\mathrm{H}_{2}$ and $\mathrm{O}_{2}$ partial pressures of $103 \mathrm{kPa}_{a b s, \text { inlet }}\left(\mathrm{i}_{\mathrm{m}}{ }^{*}\right)$. The last column shows the Tafel slopes. Mass activities and Tafel slopes were obtained from Figure 1b, i. e., after correction for the HFR, for the effective proton conduction resistance in the electrodes, and for the $\mathrm{H}_{2}$ crossover. The indicated variation represents the standard deviation from two independent measurements.

\begin{tabular}{|c|c|c|c|c|c|}
\hline $\mathrm{wt} \% \mathrm{H}_{2} \mathrm{O}$ in Solvent & Cathode $\mathrm{L}_{\mathrm{Pt}}\left[\mathrm{mg}_{\mathrm{Pt}} / \mathrm{cm}^{2}{ }_{\mathrm{geo}}\right]$ & $\operatorname{ECSA}\left[\mathrm{m}^{2} / \mathrm{g}_{\mathrm{Pt}}\right]$ & $\mathrm{i}_{\mathrm{m}}\left[\mathrm{A} / \mathrm{g}_{\mathrm{Pt}}\right]$ & $\mathrm{i}_{\mathrm{m}} *\left[\mathrm{~A} / \mathrm{g}_{\mathrm{Pt}}\right]$ & TS $[\mathrm{mV} / \mathrm{dec}$ \\
\hline \multicolumn{6}{|l|}{ in 1-propanol } \\
\hline 16 & $0.32 \pm 0.01$ & $46 \pm 2$ & $112 \pm 3$ & $88 \pm 3$ & $71 \pm 1$ \\
\hline 40 & $0.27 \pm 0.01$ & $46 \pm 2$ & $88 \pm 4$ & $69 \pm 4$ & $83 \pm 4$ \\
\hline 65 & $0.32 \pm 0.05$ & $42 \pm 2$ & $78 \pm 9$ & $61 \pm 9$ & $93 \pm 2$ \\
\hline \multicolumn{6}{|l|}{ in 2-propanol } \\
\hline 16 & $0.33 \pm 0.02$ & $35 \pm 2$ & $90 \pm 6$ & $71 \pm 6$ & $75 \pm 3$ \\
\hline 40 & $0.30 \pm 0.03$ & $36 \pm 2$ & $87 \pm 9$ & $68 \pm 9$ & $85 \pm 4$ \\
\hline
\end{tabular}

Dynamic light scattering $($ DLS $)$. - The effect of the water content in 2-propanol or 1-propanol (reagent grade, Sigma Aldrich)/water mixture solutions containing the 700 EW PFSA ionomer on the hydrodynamic diameter of the ionomer was evaluated by varying the water concentration from $16 \mathrm{wt} \%$ to $65 \mathrm{wt} \% .5 \mathrm{ml}$ of ionomer solution were placed in an $8 \mathrm{ml}$ flask with $5 \mathrm{~mm} \mathrm{ZrO}_{2}$ beads $(16.5 \mathrm{~g})$ and left on a roller mixer at $60 \mathrm{rpms}$ for $18 \mathrm{~h}$ at room temperature, mimicking the catalyst ink mixing. In all cases, the ionomer content in these solutions without added catalyst corresponds to the concentration of ionomer which one would obtain in a catalyst ink with an $\mathrm{I} / \mathrm{C}$ mass ratio of $0.65 / 1.0$ and a carbon content of $50 \mathrm{mg}_{\mathrm{c}} / \mathrm{ml}_{\text {ink }}$ (i.e., $32 \mathrm{mg}_{\text {ionomer }} / \mathrm{ml}_{\text {ink }}$ ).

After the mixing step, the hydrodynamic diameter distribution of the solutions were determined by dynamic light scattering (DLS), using a NANO-flex $180^{\circ}$ DLS particle sizer (Microtrac, Germany) with a laser wavelength of $780 \mathrm{~nm}$. Each sample was measured at room temperature 5 times for 60 seconds and the average distribution was calculated. The hydrodynamic diameter is based on the Stokes-Einstein equation, which depends on the viscosity and the refractive index of the solvent and the temperature of the sample. The temperature of each sample was measured during the particle size measurement automatically. For the calculation of the particle size distribution, we assume an irregular particle shape and a refractive index similar to Nafion (viz., 1.34). ${ }^{30}$

\section{Results and Discussion}

Fuel cell performance analysis.-As mentioned in the introduction, MEAs were prepared successfully from 5 different catalyst inks with varying water content and solvent type in order to examine whether this might influence the ionomer distribution in the catalyst layer. All cathode electrodes had similar Pt loading $(0.30 \pm-0.03$ $\mathrm{mg}_{\mathrm{Pt}} / \mathrm{cm}^{2}{ }_{\text {geo }}$ ) and their detailed specifications, including their electrochemically active surface area (ECSA) are summarized in Table 1 . The ionomer to carbon weight ratio (I/C) was kept constant at $0.65 / 1.0$ for all cases. The uncorrected $\mathrm{H}_{2} / \mathrm{O}_{2}$ polarization curves at $80^{\circ} \mathrm{C}, 100 \%$ $\mathrm{RH}$, and $170 \mathrm{kPa}_{\mathrm{abs}}$ inlet pressure as well as the corresponding HFR values are depicted in Figure 1a. Figure $1 \mathrm{~b}$ shows the $\mathrm{H}_{2} / \mathrm{O}_{2}$ performance vs. the logarithm of the cathode Pt-mass normalized current density (in units of $\mathrm{A} / \mathrm{g}_{\mathrm{Pt}}$ ), corrected for the HFR, the effective cathode proton transport resistance $\left(R_{\mathrm{H}+\text {,cath }}^{\text {eff }}\right.$; calculated from $\rho_{\mathrm{H}+\text {,cath }}$ in Figure 3), and the $\mathrm{H}_{2}$ crossover $\left(4 \pm 0.5 \mathrm{~mA} / \mathrm{cm}^{2}\right.$ geo $)$, i.e., an analogous correction which had been applied previously. ${ }^{25}$ For each ink composition, two MEAs were prepared and tested to check for reproducibility, with the error bars corresponding to the standard deviation between those two measurements.

The ORR mass activity values $\left(i_{m}\right)$ for the $46.9 \mathrm{wt} \% \mathrm{Pt} / \mathrm{C}_{\mathrm{g}}$ based cathodes were extracted from Figure $1 \mathrm{~b}$ and are summarized in Table I. In addition, to facilitate a comparison with the literature, the here obtained ORR mass activities at a total pressure of 170 $\mathrm{kPa}_{\mathrm{abs} \text {,inlet }}$ (i.e., $\mathrm{O}_{2}$ and $\mathrm{H}_{2}$ partial pressures of $123 \mathrm{kPa}_{\mathrm{abs} \text {,inlet }}$ ) were also converted to those ORR mass activities $\left(\mathrm{i}_{\mathrm{m}}{ }^{*}\right)$ which would be obtained at a cell pressure of $150 \mathrm{kPa}_{\text {abs,inlet }}$ (i.e., $\mathrm{O}_{2}$ and $\mathrm{H}_{2}$ partial pressures of $103 \mathrm{kPa}_{\text {abs,inlet }}$ ) using Equation 12 from Ref 31 . As can be seen, the mass activities of the $\mathrm{Pt} / \mathrm{C}_{\mathrm{g}}$ catalyst changes with the ink composition, decreasing noticeably with increasing water content for the 1-propanol/water inks, which indicates that the ink composition affects MEA performance even in pure $\mathrm{O}_{2}$ and at very low current densities. In general, however, the ORR mass activity of all MEAs are in good accordance with literature values reported for $46.9 \mathrm{wt} \% \mathrm{Pt} / \mathrm{C}^{32}$
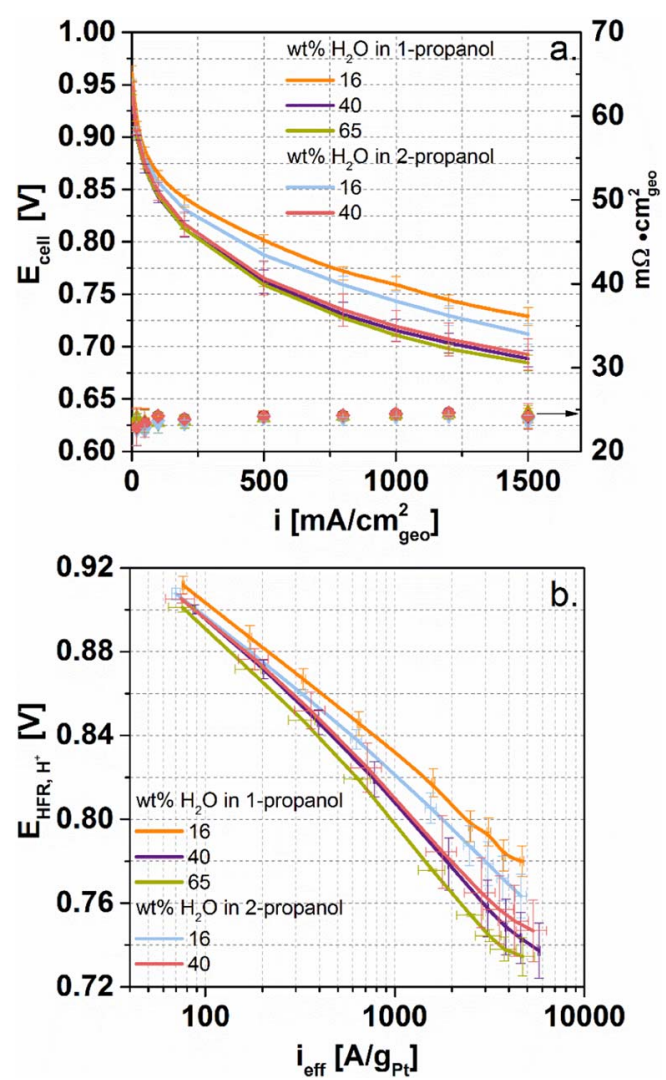

Figure 1. $\mathrm{H}_{2} / \mathrm{O}_{2}$ performance $\left(\mathrm{s}_{\mathrm{H} 2} / \mathrm{s}_{\mathrm{O} 2}=2.0 / 9.5\right)$ of MEAs with Pt cathode loadings of $0.27-0.33 \mathrm{mg}_{\mathrm{Pt}} / \mathrm{cm}^{2}{ }_{\text {geo }}$ (s. Table I) at $80^{\circ} \mathrm{C}, 100 \% \mathrm{RH}$, and $p_{\text {cell }}=170 \mathrm{kPa}_{\mathrm{abs}}$,inlet for the $46.9 \mathrm{wt} \% \mathrm{Pt} / \mathrm{C}_{\mathrm{g}}$ cathode catalyst at an $\mathrm{I} / \mathrm{C}$ mass ratio of $0.65 / 1.0$. The cathode catalyst layers were manufactured using catalyst inks with different water content $\left(16-65 \mathrm{wt} \% \mathrm{H}_{2} \mathrm{O}\right)$ and organic solvents (1propanol and 2-propanol). a. uncorrected performance curves (left y-axis) with their corresponding HFR (right $y$-axis); $b$. performance curves referenced to the Pt-mass normalized current density corrected for HFR, $\mathrm{H}^{+}$conduction resistance in the cathode $\left(\mathrm{R}_{\mathrm{H}+\text {,cath }}^{\text {eff }}\right)$, and the $\mathrm{H}_{2}$ crossover current. Anode $\mathrm{Pt}$ loadings were $0.1 \mathrm{mg}_{\mathrm{Pt}} / \mathrm{cm}^{2}{ }_{\text {geo }}$ and the error bars correspond to the standard deviation between two independent measurements on two different MEAs (horizontal error bars are due to small variations in the Pt loading). 
and other carbon supported platinum catalysts. ${ }^{33}$ Tafel slopes were determined from Figure $1 \mathrm{~b}$ between 50 and $500 \mathrm{~mA} / \mathrm{cm}^{2}(\sim 150$ and $\sim 2000 \mathrm{~A} / \mathrm{g}_{\mathrm{Pt}}$ in Figure $1 \mathrm{~b}$ ), following the approach by Neyerlin et al., ${ }^{31}$ who only evaluated Tafel slopes for current densities greater than 10 times the $\mathrm{H}_{2}$ crossover current density and up to below $1 \mathrm{~A} / \mathrm{cm}^{2}$. The Tafel slopes (TS) of all cathode electrodes range between 71 and $93 \mathrm{mV} / \mathrm{dec}$. (s. Table I). The only electrode which gives a TS close to the theoretical value of $70 \mathrm{mV} / \mathrm{dec}$. (i.e., based on a transfer coefficient of $\alpha=1$ ) is the one manufactured using an ink based on $16 \mathrm{wt} \% \mathrm{H}_{2} \mathrm{O}$ in 1-propanol, for which also the highest mass activity is observed. We ascribe the higher Tafel slopes to severe mass transport losses, caused by an inhomogeneous ionomer distribution in the electrode and a concomitant severe blockage of the pores in the electrodes, for which we will provide microscopic evidence below. In addition, there is a significant difference in the ECSA values between catalyst layers manufactured in 1-propanol vs. 2-propanol. All electrodes formulated using 1-propanol based inks exhibit higher ECSAs, which also suggests a better ionomer distribution throughout the catalyst layer. However no dependence of the ECSA for each solvent with respect to the water content in the inks is observed.

To determine the $\mathrm{H}_{2}$ /air performance of MEAs, air polarization curves were measured under stoichiometric flows $\left(\mathrm{s}_{\mathrm{H} 2} / \mathrm{s}_{\text {air }}=1.5 / 2.0\right)$ at $170 \mathrm{kPa}_{\text {abs,inlet }}$ under both "dry" $\left(80^{\circ} \mathrm{C}\right.$ and $\left.30 \% \mathrm{RH}\right)$ and "wet" $\left(60^{\circ} \mathrm{C}\right.$ and $100 \% \mathrm{RH}$ ) conditions. For means of comparability with literature data, polarization curves at $80^{\circ} \mathrm{C}$ and $100 \% \mathrm{RH}$ are also provided in the supporting information (S2). Figure 2 shows the effect of the ionomer distribution on the MEA performance under "dry" (Figure 2a) and "wet" conditions (Figure 2b). In the case of "dry" conditions, it is expected that an inhomogeneous ionomer distribution would lead to insufficient proton conduction pathways through the catalyst layer, lowering MEA performance. The performance at "dry" conditions $\left(80^{\circ} \mathrm{C}\right.$ and $\left.30 \% \mathrm{RH}\right)$ of the catalyst layers based on 1-propanol inks is superior compared to the 2-propanol based ones. In addition, the performance of the former is best at the lowest water content in the ink (orange line), which we hypothesize is due to a more homogeneous ionomer distribution on the carbon support, providing superior proton conductive pathways through the electrode structure.

In the case of "wet" conditions $\left(60^{\circ} \mathrm{C}\right.$ and $\left.100 \% \mathrm{RH}\right)$, it is expected due to the swelling of the ionomer in the presence of liquid water, that the blockage of gas transport channels within the electrode would be aggravated. This is clearly shown in Figure $2 b$, where the $\mathrm{H}_{2}$ /air performance under wet conditions becomes very poor for MEAs which were prepared with high water content inks. This could be explained by assuming that for an inhomogeneous ionomer distribution in the cathode electrode, $\mu \mathrm{m}$-scale patches of ionomer might form and could then lead to high $\mathrm{O}_{2}$ transport resistances across the electrode thickness, resulting in the observed performance decrease at high current densities. The performance difference between the catalyst layer prepared from the $16 \mathrm{wt} \% \mathrm{H}_{2} \mathrm{O}$ in 1-propanol based ink (orange line) and the MEAs prepared with the other ink compositions is related to a difference in ionomer homogeneity in both the macroand micro/mesopores of the catalyst layer, as will be quantified and discussed in the following sections.

The proton resistivity of the different cathodes was measured according to the method developed by Liu et al. ${ }^{34}$ The scope of this analysis is to determine whether there is any correlation between the qualitative differences in the ionomer distribution deduced from the polarization curves and the proton conduction resistance of the cathodes prepared in this study. To account for the slight deviations in cathode loadings, sheet resistance values $\left(R_{\mathrm{H}+\text {,cath }}\right)$ obtained via impedance spectroscopy were divided by the respective electrode thicknesses calculated from the carbon loadings, $L_{\mathrm{C} \text {,cath }}$, (assuming a thickness of $28 \mu \mathrm{m}$ per $\left.1 \mathrm{mg}_{\mathrm{C}} \mathrm{cm}^{-2}\right)^{27}$ as described by Equation 2 .

$$
\rho_{\mathrm{H}+\text { cath }}=\frac{R_{\mathrm{H}+\text {, cath }}}{28 \mu \mathrm{m}\left(\frac{\mathrm{mg}_{\mathrm{C}}}{\mathrm{cm}^{2}}\right)^{-1} \cdot L_{\mathrm{C}, \text { cath }}}
$$

Figure 3 shows the electrode proton resistivities, $\rho_{\mathrm{H}+\text {,cath }}$, as a function of RH. While the expected trend with respect to different RH
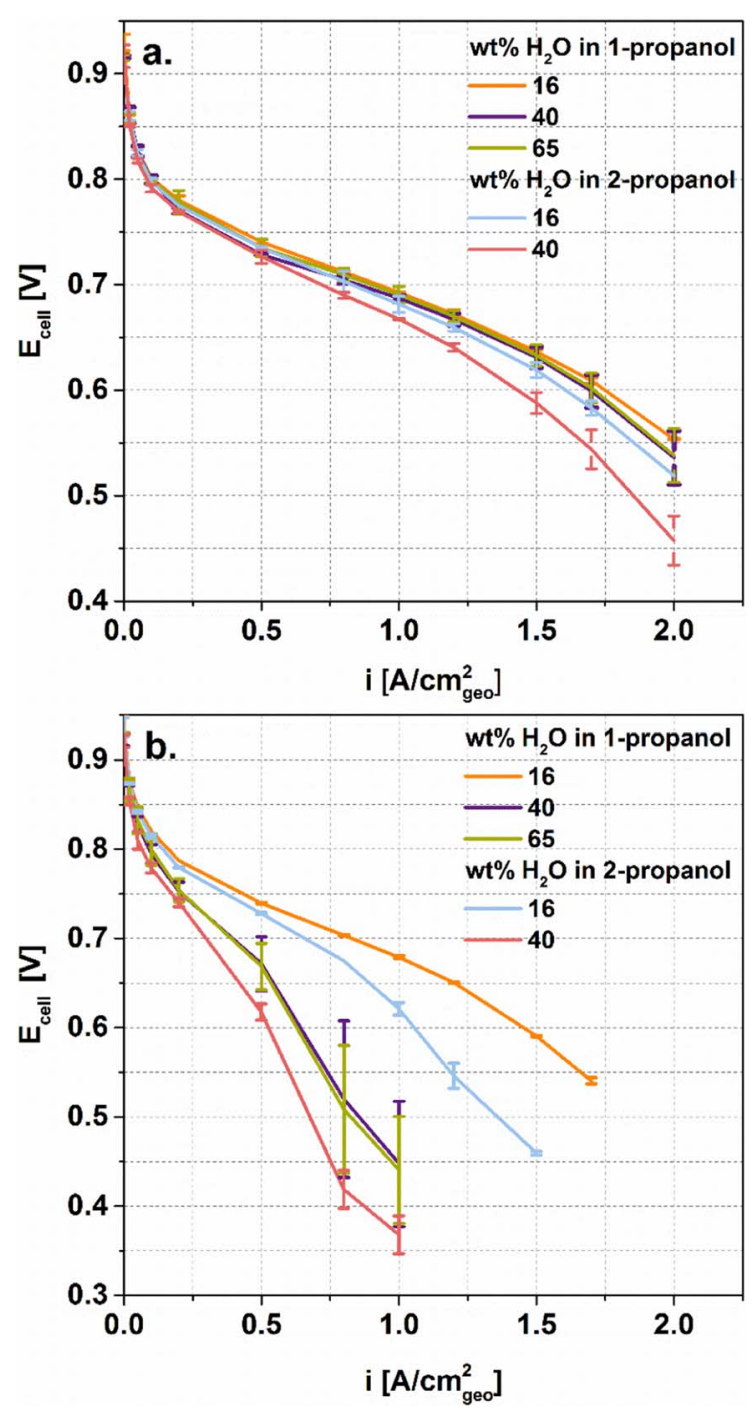

Figure 2. $\mathrm{H}_{2} /$ Air performance $\left(\mathrm{s}_{\mathrm{H} 2} / \mathrm{s}_{\mathrm{air}}=1.5 / 2.0\right)$ of MEAs with Pt cathode loadings of $0.27-0.33 \mathrm{mg}_{\mathrm{Pt}} / \mathrm{cm}^{2}$ geo $\left(\mathrm{s}\right.$. Table I) for the $46.9 \mathrm{wt} \% \mathrm{Pt} / \mathrm{C}_{\mathrm{g}}$ cathode catalyst at an I/C mass ratio of $0.65 / 1.0$. The cathode catalyst layers were manufactured using catalyst inks with different water content (16-65 wt\% $\mathrm{H}_{2} \mathrm{O}$ ) and organic solvents (1-propanol and 2-propanol). a. at $80^{\circ} \mathrm{C}, 30 \% \mathrm{RH}$, and $p_{\text {cell }}=170 \mathrm{kPa}_{\mathrm{abs}, \text { inlet }} ; \mathrm{b}$. at $60^{\circ} \mathrm{C}, 100 \% \mathrm{RH}$, and $p_{\text {cell }}=170 \mathrm{kPa}_{\text {abs,inlet }}$. Anode Pt loadings were $0.1 \mathrm{mg}_{\mathrm{Pt}} / \mathrm{cm}^{2}$ geo and the error bars correspond to the standard deviation between two independent measurements on two different MEAs.

conditions is observed,${ }^{34}$ surprisingly, no systematic correlation with the ink recipe can be observed, since the variation in $\rho_{\mathrm{H}+\text {,cath }}$ is within the error of the measurement. This means in turn that the large differences in the $\mathrm{H}_{2}$ /air performance which strongly depend on the cathode preparation procedure (s. Figure 2), are not reflected in the measured proton conduction resistance in the different cathodes which yields essentially identical values for all ink compositions used for MEA preparation. This can be understood by first discussing the fundamental relationship between proton resistivity and electrode properties. This is given by Equation 3 that quantifies the relationship between the proton resistivity of an electrode with the proton conductivity of the ionomer $\left(\sigma_{H+\text {,ionomer }}\right)$, the tortuosity of the ionomer phase $\left(\tau_{\text {ionomer }}\right)$, and the volume fraction of the ionomer in the electrode $\left(\varepsilon_{\text {ionomer }}\right)$.

$$
\rho_{\mathrm{H}+, \text { cath }}=\frac{1}{\sigma_{\mathrm{H}+\text {,ionomer }}} \cdot \frac{\tau_{\text {ionomer }}}{\varepsilon_{\text {ionomer }}}
$$

In other words, $\rho_{\mathrm{H}+\text {,cath }}$ depends on the tortuosity of the ionomer network inside the catalyst layer, but does not necessarily reflect the 


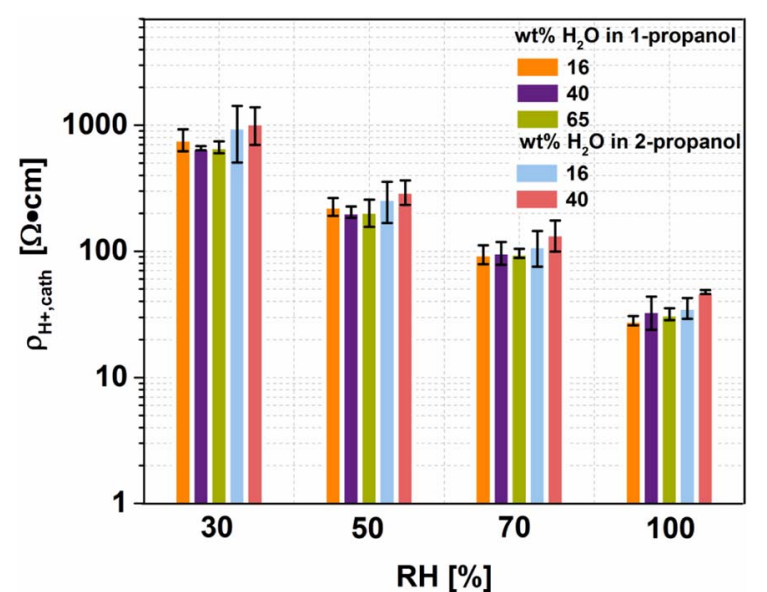

Figure 3. The effect of the catalyst ink composition used for the preparation of the cathode catalyst layer on the cathode proton resistivity $\left(\rho_{\mathrm{H}+\text {,cath }}\right) \mathrm{de}-$ termined by AC impedance analysis (see Experimental section) at different relative humidities $(\mathrm{RH})$. The error bars correspond to the standard deviation between independent measurements with two different MEAs.

ionomer distribution over the surface of the carbon support and the catalytically active platinum surface. For example, Figure 4a illustrates an electrode with an idealized homogeneous ionomer distribution on the catalyst surface, which would allow optimal proton transport to each individual platinum particle as well as across the entire electrode thickness. Both transport pathways are required for wellperforming electrodes, for which the apparent tortuosity approaches values of $\tau_{\text {ionomer }} \sim 1$ for I/C mass ratios exceeding $\sim 0.6 / 1^{26}$. On the other hand, an essentially identical ionomer tortuosity would be expected for an entirely inhomogeneous ionomer distribution in the electrode, as sketched in Figure 4b, which in turn would imply that also the measured proton resistivity would be the same as that for the electrode morphology sketched in Figure 4a (based on Equation 2, given that $\sigma_{H+\text {,ionomer }}$ and $\varepsilon_{\text {ionomer }}$ are kept equal). Therefore, the homogeneity of the ionomer on the catalyst surface cannot necessarily be deduced from proton resistivity measurements. Thus, despite a comparable proton resistivity across the electode, the ionomer distribution sketched in Figure $4 \mathrm{~b}$ would result in poor platinum utilization, especially under "dry" operating conditions, as well as high oxygen mass transport resistances if $\mu \mathrm{m}$-scale ionomer patches are formed, both effects resulting in a poor $\mathrm{H}_{2}$ /air performance.

Ionomer distribution in the macropores of the catalyst layer.To quantify the ionomer inhomogeneity in the catalyst layer, SEM micrographs of the cathodic electrodes were obtained. As described in the experimental section, the decals were transferred onto the membrane via a hot pressing procedure, whereby the back side of the electrode after removal of the PTFE transfer film was imaged (i.e., the side of the electrode that would be facing the diffusion medium after cell assembly). Figure 5 shows representative micrographs for each type of electrode, prepared with different ink compositions. Thin $\mu \mathrm{m}$-sized patches of ionomer layer are observed to cover parts of the catalyst layer surface for all ink compositions, except for the $16 \mathrm{wt} \%$ $\mathrm{H}_{2} \mathrm{O}$ in 1-propanol based CL. These "ionomer patches" (outlined in white straight line) clearly block the macropores of the catalyst layer, from which one would expect that they substantially hinder oxygen mass transport through the electrode, especially under "wet" operating conditions when the ionomer is swelling due to high water uptake ${ }^{35}$ and when parts of the electrode pores may additionally be flooded by liquid water. Qualitatively, the extent of the appearance of ionomer patches increases with the water content in the inks and, for equal water content, a higher frequency of appearance of ionomer patches is observed for cathodes prepared from 2-propanol vs. 1-propanol based inks. This observed order is consistent with the $\mathrm{H}_{2}$ /air performance under wet conditions (see Figure 2b), i.e., the larger and the a.

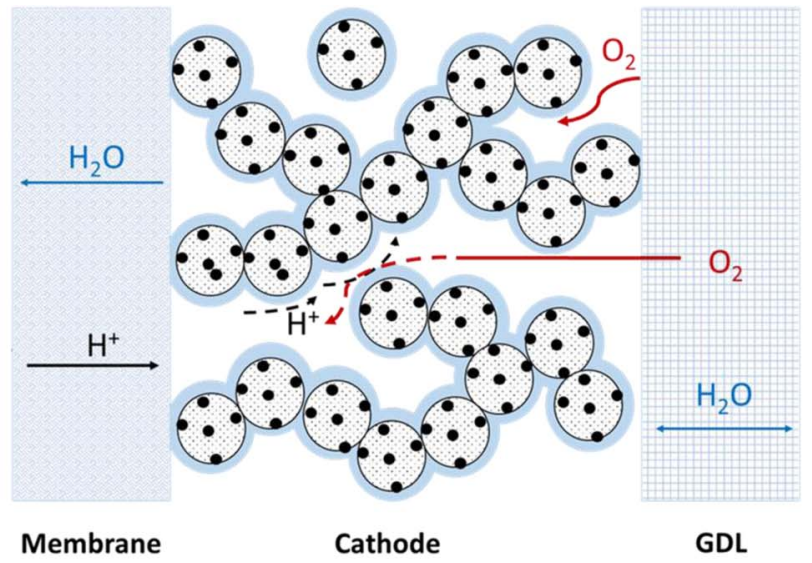

b.

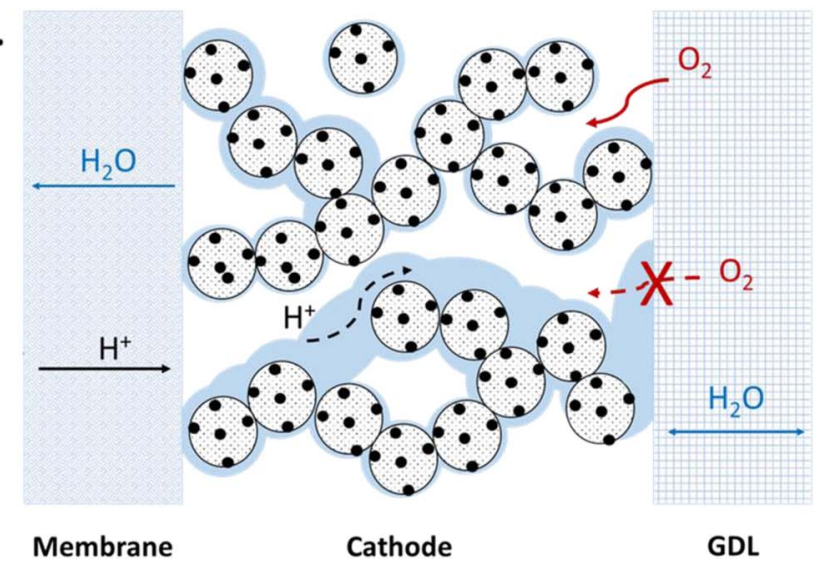

Figure 4. Schematic representation of different ionomer distributions in a catalyst layer: a. idealized homogeneous ionomer coverage over the catalyst surface; b. inhomogeneous ionomer distribution across the catalyst layer. Here, gray dotted spheres represent the primary particles of the carbon support, black sphere represent the Pt nanoparticles, and blue colored areas in the cathode electrode represent the ionomer film.

more frequent the observed ionomer patches, the poorer is the $\mathrm{H}_{2} / \mathrm{air}$ performance.

To more quantitatively describe the coverage of the electrode surface by the observed ionomer patches, we analyzed three micrographs for each cathode catalyst layer type. Figure 6 shows the fractional coverage of the electrode surface with ionomer patches, averaged over always one entire micrograph for each CL prepared from different inks (three micrographs per ink). Quite clearly, for the CL prepared from the ink based on $16 \mathrm{wt} \% \mathrm{H}_{2} \mathrm{O}$ in 1-propanol, a very small fraction of the electrode is covered by ionomer patches (none observed in 2 micrographs and $\sim 6 \%$ in one micrograph; see orange bar), while between $\sim 36-45 \%$ of the electrode surface is covered by ionomer patches for the CL prepared from the ink based on $40 \mathrm{wt} \% \mathrm{H}_{2} \mathrm{O}$ in 2-propanol (see pink bars). The average fractional ionomer coverage for the other three cathode CL types (see dashed horizontal lines in Figure 6) are in between these values, namely $\sim 22 \%$ for the CLs based on inks with 40 and $65 \mathrm{wt} \% \mathrm{H}_{2} \mathrm{O}$ in 1-propanol and $\sim 15 \%$ for the $\mathrm{CL}$ based on an ink with $16 \mathrm{wt} \% \mathrm{H}_{2} \mathrm{O}$ in 2-propanol. The fact that an increase of the average fractional coverage with ionomer patches for the different cathode CLs (dashed horizontal bars in Figure 6) directly reflects the decrease in their $\mathrm{H}_{2}$ /air performance under wet conditions (Figure $2 b$ ), provides very strong evidence that the observed ionomer patches indeed are responsible for the observed differences in the $\mathrm{H}_{2} /$ air performance. This trend is also reflected by the size distribution of the ionomer patches, which we obtained from the analysis of three micrographs per cathode CL type (see Figure 7): only very small ionomer patches are observed for the CL based on the 

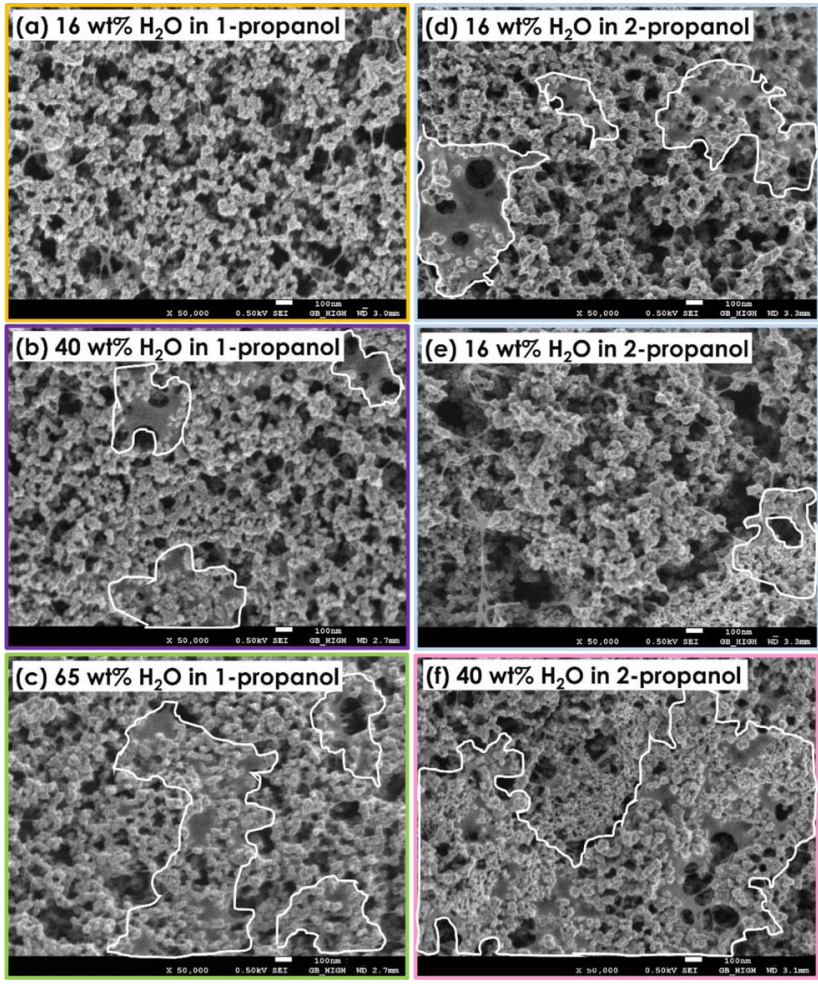

Figure 5. SEM micrographs of the back side of the electrodes after removal of the PTFE transfer film (i.e., the side of the electrode that would be facing the diffusion medium after cell assembly), taken for electrodes prepared from different inks based on: a. $16 \mathrm{wt} \% \mathrm{H}_{2} \mathrm{O}$ in 1-propanol (orange); b. $40 \mathrm{wt} \%$ $\mathrm{H}_{2} \mathrm{O}$ in 1-propanol (purple); c. $65 \mathrm{wt} \% \mathrm{H}_{2} \mathrm{O}$ in 1-propanol (green); d. and e. $16 \mathrm{wt} \% \mathrm{H}_{2} \mathrm{O}$ in 2-propanol (light blue); f. $40 \mathrm{wt} \% \mathrm{H}_{2} \mathrm{O}$ in 2-propanol (pink). Electrodes are comprised of a Pt-loaded graphitized high-structure and high-surface area carbon support and low-EW ionomer, and the images show $\sim 50-300 \mathrm{~nm}$ secondary pores formed by the primary agglomerates of the carbon-support.

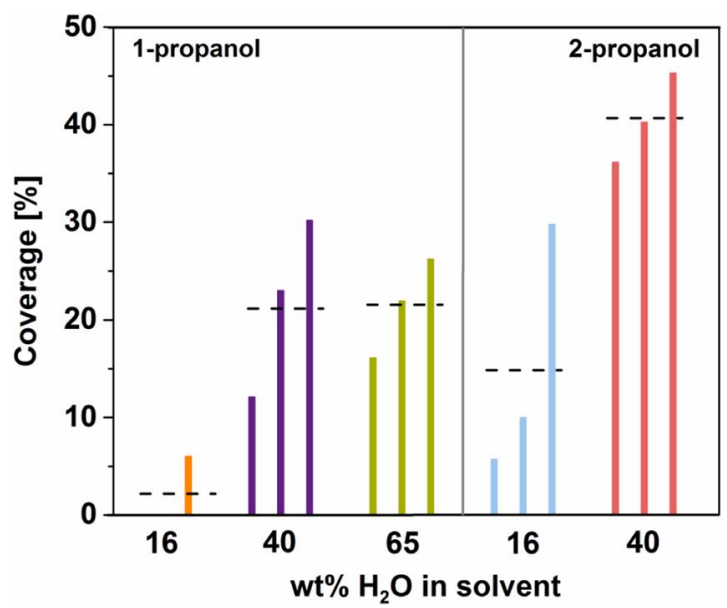

Figure 6. Coverage of the electrode's upper surface (GDL facing side) with ionomer "patches" determined from SEM pictures like those shown as representative examples in Figure 5. The coverage was calculated by measuring by the area that the ionomer patches cover within a single micrograph divided by the area of the respective micrograph. Each column corresponds to one micrograph of each sample, whereby for each sample, three micrographs of the same magnification were chosen. Going from left to right, the bars represent measurements on cathodes prepared with inks composed of: $16 \mathrm{wt} \% \mathrm{H}_{2} \mathrm{O}$ in 1-propanol (orange); $40 \mathrm{wt} \% \mathrm{H}_{2} \mathrm{O}$ in 1-propanol (purple); $65 \mathrm{wt} \% \mathrm{H}_{2} \mathrm{O}$ in 1-propanol (green); $16 \mathrm{wt} \% \mathrm{H}_{2} \mathrm{O}$ in 2-propanol (light blue); $40 \mathrm{wt} \% \mathrm{H}_{2} \mathrm{O}$ in 2-propanol (pink). The dashed horizontal lines represent the average ionomer coverage for each cathode CL type.

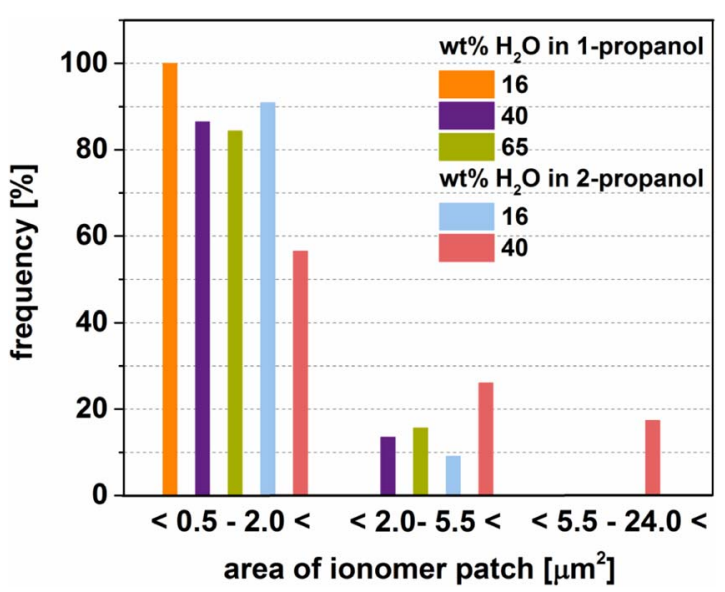

Figure 7. Size distribution of the ionomer patches with respect to different solvent and water content in the inks from which the cathode CLs were prepared. The area of each ionomer patch was calculated from the same micrographs used in Figure 6. For each CL type, three micrographs of the same magnification were chosen. Going from left to right, the bars represent measurements on cathodes prepared with inks composed of: $16 \mathrm{wt} \% \mathrm{H}_{2} \mathrm{O}$ in 1-propanol (orange); $40 \mathrm{wt} \% \mathrm{H}_{2} \mathrm{O}$ in 1-propanol (purple); $65 \mathrm{wt} \% \mathrm{H}_{2} \mathrm{O}$ in 1-propanol (green); $16 \mathrm{wt} \% \mathrm{H}_{2} \mathrm{O}$ in 2-propanol (light blue); $40 \mathrm{wt} \% \mathrm{H}_{2} \mathrm{O}$ in 2-propanol (pink).

ink with $16 \mathrm{wt} \% \mathrm{H}_{2} \mathrm{O}$ in 1-propanol, while a substantial fraction of very large ionomer patches is observed for the CL based on the ink with $40 \mathrm{wt} \% \mathrm{H}_{2} \mathrm{O}$ in 2-propanol.

Ionomer distribution in micro- and mesopores of the catalyst layer.-While the analysis of $\mu \mathrm{m}$-sized ionomer patches correlates very well with the oxygen transport properties of the electrodes under wet operating conditions, a better understanding with regard to the local proton transport to the platinum nanoparticles requires a more detailed investigation of the ionomer distribution in the electrode. Therefore, we investigated the microstructure changes of the catalyst before and after ionomer addition with various ink compositions by means of $\mathrm{N}_{2}$ adsorption analysis. ${ }^{36-38}$ As described in the experimental section, for catalyst/ionomer composites, catalyst layers were coated onto PTFE using various ink compositions, dried, and then the coatings were scratched off from the substrate and measured. The $\mathrm{N}_{2}$ adsorption isotherms of the pristine carbon black (the same EA-type graphtized Ketjen Black that serves as support for the $46.9 \mathrm{wt} \% \mathrm{Pt} / \mathrm{C}_{\mathrm{g}}$ catalyst), catalyst ( $46.9 \mathrm{wt} \% \mathrm{Pt} / \mathrm{C}_{\mathrm{g}}$ ) without and with ionomer (i.e., with the catalyst layer formulated from $16 \mathrm{wt} \% \mathrm{H}_{2} \mathrm{O}$ in 1-propanol) are provided for the reader's convenience in the supporting information (see Figure S3). The pristine carbon black and the catalyst exhibited larger amounts of $\mathrm{N}_{2}$ adsorbed compared to the samples that contained ionomer, particularly in the micropore regions (i.e., at $<0.01 \mathrm{p} / \mathrm{p}_{0}$, see Figure S3a). This is to be expected, as the ionomer will primarily block the micropores and mesopores, leading to a significant reduction of the accessible pores and to lower overall absorption values, as reported previously. ${ }^{36,38}$ Looking at the carbon normalized $\mathrm{N}_{2}$ adsorption isotherms (see Figure $\mathrm{S} 3 \mathrm{~b}$ ), all samples exhibit similar hysteresis behavior during the desorption process. The hysteresis is characteristic of the cavitation mechanism of nitrogen condensed in the pores, for which the desorption step is shifted to a lower relative pressure, ca. $0.45 \mathrm{p} / \mathrm{p}_{0}$; this behavior is typical for ink-bottle-pores with narrow necks. ${ }^{39}$ Even though all catalyst layer samples show similarly shaped $\mathrm{N}_{2}$ adsorption isotherms, differences in the pore structure are observed for the different ink-recipes. These changes in the microstructure can be linked with ionomer distribution in the CL and will be discussed in the following.

The pore size distribution curves are very similar in shape. For all the here examined cases, the $\mathrm{N}_{2}$-adsorption isotherm exhibits a hysteresis loop that will give rise to two different pore size distributions 

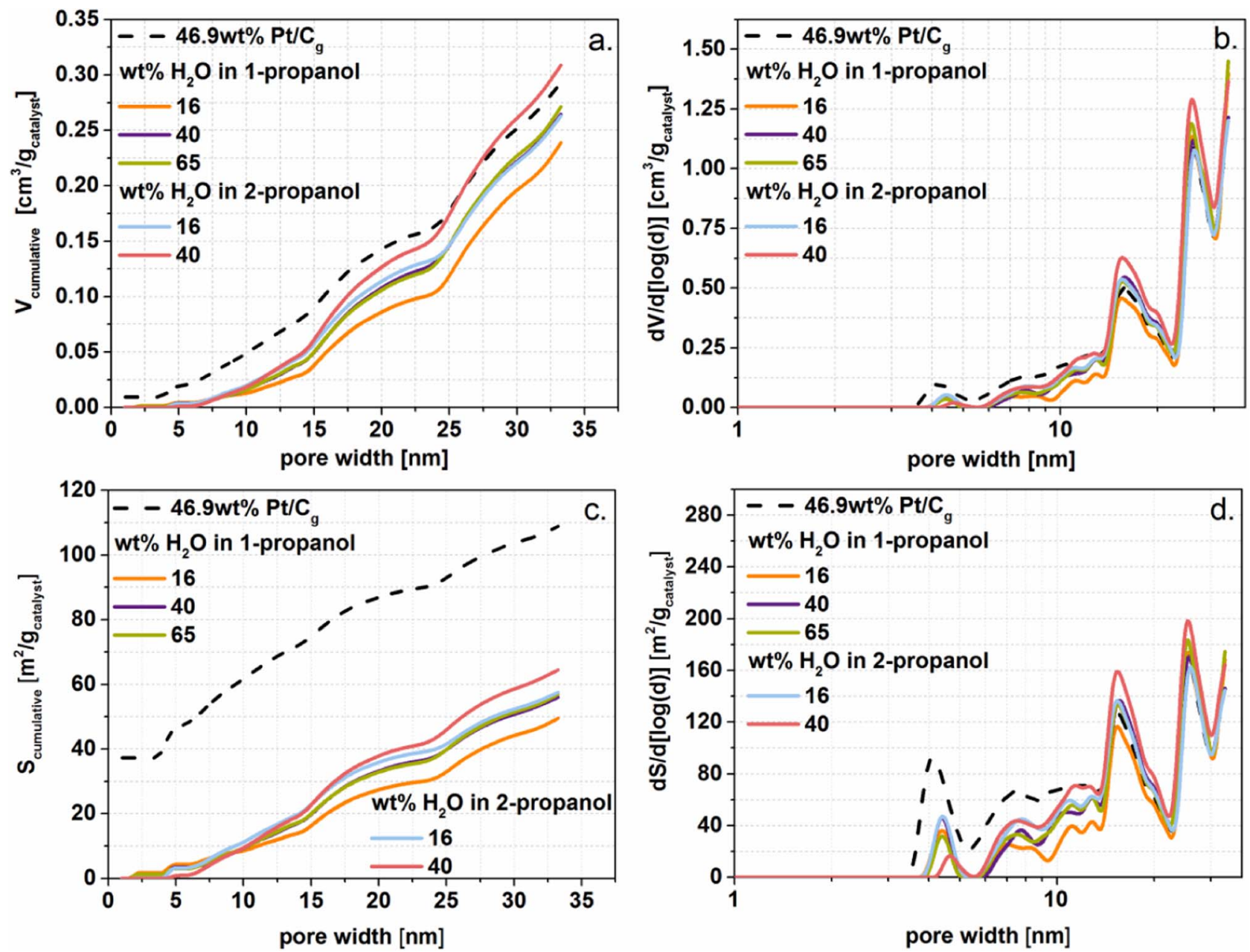

Figure 8. Catalyst mass normalized pore volume and pore area distributions of the catalyst/ionomer composites prepared with different ink compositions calculated by the QSDFT model and based on the adsorption branch. For comparison reasons the pristine $46.9 \mathrm{wt} \% \mathrm{Pt} / \mathrm{C}_{\mathrm{g}}$ catalyst (black dotted line) was also added to the graphs. a. Cumulative volume vs. pore diameter; b. derivative of pore volume with respect to the logarithm of the pore diameter vs. the pore diameter plotted on a logarithmic scale; c. cumulative surface vs. pore diameter; and, d. derivative of the pore surface with respect to the logarithm of the pore diameter vs. the pore diameter plotted on a logarithmic scale.

depending on whether adsorption (without step) or desorption (with the step) is used. Since it is known that the step in the desorption branch is an artefact not related to pore size at all, ${ }^{39,40}$ our calculations are based on the adsorption branch. The slit QSDFT model is based on the completely reversible micropore region of an activated carbon, and as such both adsorption and equilibrium branches of the isotherm would be identical. However, our samples are best described by a series of interconnected cylinders, or cylinder/slit pores network. The hysteresis of the desorption branch of the $\mathrm{N}_{2}$ adsorption isotherm suggests mostly a mesopore structure (inter-particle voids between carbon particles), in which a small proportion is accessible through micropore-sized channels - it is this connectivity that gives rise to the almost parallel nature of the hysteresis in the near horizontal region which terminates in the "closing step" around $0.45 \mathrm{p} / \mathrm{p}_{0}$ (see, e.g., Figure S3). This effect is due to the cavitation of liquefied adsorbate in the mesopores at a pressure limited by the fluid properties of the condensed phase.

Table II depicts the BET areas and the results from the QSDFT calculation of the pore volume and the surface area, referenced both to the sample weight and the catalyst weight. It is obvious that the specific surface area calculated from the BET model is systematically larger than the one obtained from QSDFT. This is similar to the observation reported by Kaneko and Ishii, ${ }^{41}$ who showed that the determination of the specific surface area of activated carbon using the BET model leads to an overestimation of the actual surface area. Puziy et al. ${ }^{42}$ observed the same phenomenon, and Ocelli et al. ${ }^{43}$ proposed that the discrepancy between $S_{\mathrm{BET}}$ and $S_{\mathrm{DFT}}$ they observed for their expanded clay catalysts originates from a contribution of the micropore volume filling to the free surface coverage in the BET model. Shi ${ }^{44}$ observed the same discrepancy between $S_{\mathrm{BET}}$ and $S_{\mathrm{DFT}}$ for a large set of activated carbon microbeads and activated fibers, and attributed this phenomenon to the fact that the nitrogen adsorbed in the micropores has a higher density than normal bulk liquid nitrogen. Thus, because of the big uncertainty in the evaluation of the BET surface, the DFT model appears to be the best way to determine the actual surface area, even though in our case the differences are not that pronounced $(\sim 15 \%)$. A closer inspection of the QSDFT derived specific surface areas in Table II reveals a clear correlation with the average fraction of ionomer patches (see horizontal dashed lines in Figure 6), namely that the specific surface area increases with an increasing fractional coverage with ionomer patches (e.g., from $49.5 \mathrm{~m}^{2} / \mathrm{g}_{\text {catalyst }}$ for the CL based on the ink with $16 \mathrm{wt} \% \mathrm{H}_{2} \mathrm{O}$ in 1-propanol, to $64.5 \mathrm{~m}^{2} / \mathrm{g}_{\text {catalyst }}$ for the $\mathrm{CL}$ based on the ink with $40 \mathrm{wt} \% \mathrm{H}_{2} \mathrm{O}$ in 2-propanol). This indicates a less effective blocking of micropores by ionomer, in cases where a large fractional coverage with ionomer patches is observed, suggesting that in these cases the ionomer is already strongly agglomerated in the ink, so that its adsorption into the micropores of the carbon support is hindered. However, for the case of $16 \mathrm{wt} \% \mathrm{H}_{2} \mathrm{O}$ in 2-propanol the specific surface area is very high even though the ionomer patches are small (Figure 6) and the performance is the second best (Figure 2). 
Table II. BET, QSDFT, and pore volumes of the pristine catalyst (bottom row) and the catalyst layers. The data are normalized by the sample weight and by the catalyst weight; the latter is done to facilitate comparison in the absence of ionomer, i.e., with the pristine catalyst.

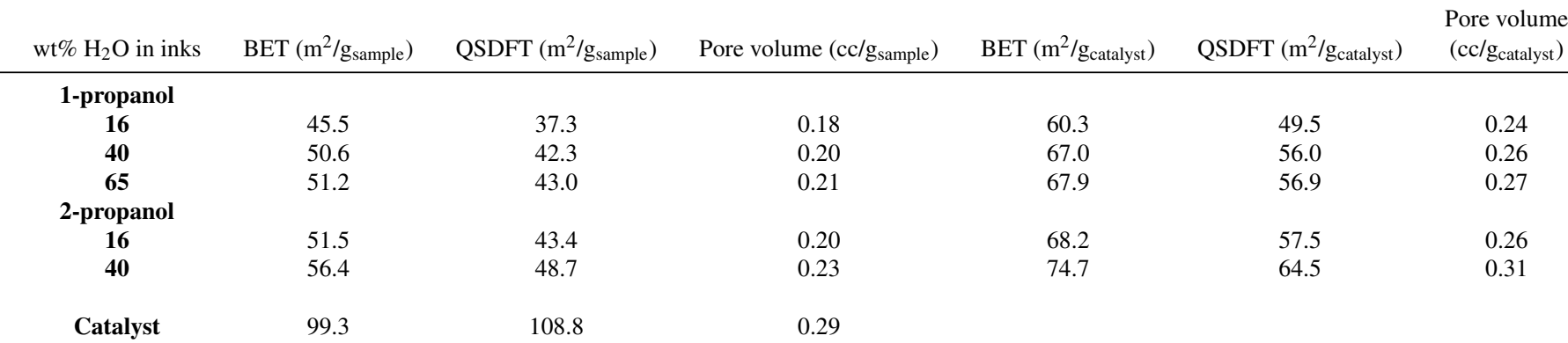

A plausible explanation could be that due to the solvent change, the ionomer interaction with carbon support has been affected and altered the ionomer distribution. In this case one could imagine the ionomer not covering entirely the carbon support as a homogeneous thin film but rather as ionomer bundles on the surface of the carbon which are still iononically connected. This in turn would lead to high specific surface area without blocking the micro/meso-pores of the carbon support and still be consistent with the cell performance.

Figure 8 shows the pore size distributions of the volume and the surface area normalized by the catalyst mass, and calculated by the QSDFT method from the adsorption branch. While the pore volume is somewhat reduced after the addition of ionomer (Figure 8a), the surface area is substantially reduced particularly in the micropore region (i.e., the pore area distribution curve of the pristine catalyst is essentially down-shifted by a constant value across the entire pore size scale; see Figure $8 \mathrm{~b}$ ). This is seen more clearly in the pore volume and area distribution curves plotted as $\mathrm{dV} / \mathrm{d}[\log (\mathrm{d})]$ or $\mathrm{dS} / \mathrm{d}[\log (\mathrm{d})]$ vs. $\log (\mathrm{d})$, for which the area under the curves is directly proportional to volume or surface area (see Figures $8 \mathrm{~b}$ and $8 \mathrm{~d}$ ). More specifically, the pore volume and the pore area of the catalyst layers are predominantly reduced in the region between $\sim 3.5-12 \mathrm{~nm}$ (micropores and lower part of mesopore region) if compared to the pristine catalyst, clearly indicating that the ionomer blocks the access to small pores. Furthermore, the catalyst layers which were prepared with the ink which resulted in the lowest fractional coverage by ionomer patches (the ink with $16 \mathrm{wt} \% \mathrm{H}_{2} \mathrm{O}$ in 1-propanol, see Figure 6) and which had the best $\mathrm{H}_{2}$ /air performance under wet conditions (see Figure $2 \mathrm{~b}$ ) showed the strongest suppression of volume and area in the $\sim 3.5-12 \mathrm{~nm}$ pore size region. The obviously very effective blocking of small pores in this case could be explained by assuming that the ionomer aggregates in this type of ink are very small, so that they can interact more intimately with the catalyst surface, thereby resulting in a more homogeneous ionomer distribution on the carbon and across the electrode. On the other hand, the $\mathrm{CL}$ with the poorest $\mathrm{H}_{2}$ /air performance under wet conditions (prepared from the ink with $40 \mathrm{wt} \% \mathrm{H}_{2} \mathrm{O}$ in 2-propanol, Figure $2 \mathrm{~b}$ ) and with the largest fractional coverage by large ionomer patches (see Figure 6), displays the highest volume and area in the $\sim 3.5-12 \mathrm{~nm}$ pore size region (see pink line in Figures $8 \mathrm{c}$ and $8 \mathrm{~d}$ ). Again, this could be explained if the ionomer aggregates in this ink were very large, suppressing the interaction of the ionomer with the catalyst surface.

Size of the low-EW ionomer aggregates in various solutions.While the ionomer aggregates cannot be determined by dynamic light scattering (DLS) in actual catalyst inks due to the high concentration of carbon, DLS can be used to gain insights into the influence of the solvent composition on the ionomer aggregates in catalyst-free ionomer/solvent mixtures which have the same ionomer concentration as in the catalyst inks used in this study (viz., $32 \mathrm{mg}_{\text {Ionomer }} / \mathrm{ml}_{\text {ink }}$ ). This ionomer concentration is too high to extract any information on the size of the primary ionomer aggregates, ${ }^{45}$ but provides information on the hydrodynamic diameter distribution of the secondary aggregates of the ionomer. At this concentration, the hydrodynamic diameter of the low-EW ionomer ranges from $\sim 70 \mathrm{~nm}$ to $\sim 2.5 \mu \mathrm{m}$ in the different solutions (see Figure 9). As reported in the literature, the hydrodynamic diameter of secondary ionomer aggregates strongly depends on the nature of the ionomer and the solvents properties. ${ }^{46-49,15,50}$ For the ionomer/solvent composition mimicking the ink used for the $\mathrm{CL}$ with the best $\mathrm{H}_{2}$ /air performance under wet conditions and the lowest fractional coverage with ionomer patches (i.e, with $16 \mathrm{wt} \% \mathrm{H}_{2} \mathrm{O}$ in 1-propanol), very small ionomer aggregates with a single peak at $\sim 70 \mathrm{~nm}$ are observed. On the other hand, the largest single peak at $\sim 2.5 \mu \mathrm{m}$ is observed for the ionomer/solvent composition mimicking the ink used for the $\mathrm{CL}$ with the worst $\mathrm{H}_{2}$ /air performance under wet conditions and the highest fractional coverage with ionomer patches (i.e, with $40 \mathrm{wt} \% \mathrm{H}_{2} \mathrm{O}$ in 2-propanol). Thus, large hydrodynamic diameters of the ionomer aggregates in ionomer/solvent mixtures (Figure 9) seem to correlate reasonably well with poor $\mathrm{H}_{2} /$ air performance under wet conditions (Figure $2 b$ ), with a large fractional coverage of ionomer patches in electrodes (Figure 6), and with a weakened suppression of micro/mesopore volume in catalyst layers (Figure 8). One exception to this correlation are the DLS data for the ionomer in $40 \mathrm{wt} \% \mathrm{H}_{2} \mathrm{O}$ in 1-propanol (purple line in Figure 9), which has a slightly better $\mathrm{H}_{2}$ /air performance under wet conditions and a lower fractional coverage with ionomer patches compared to the $40 \mathrm{wt} \% \mathrm{H}_{2} \mathrm{O}$ in 2-propanol mixture, even though its DLS derived size distribution is essentially identical. Nevertheless, it is rather obvious that small ionomer aggregates are essential for good $\mathrm{H}_{2}$ /air performance.

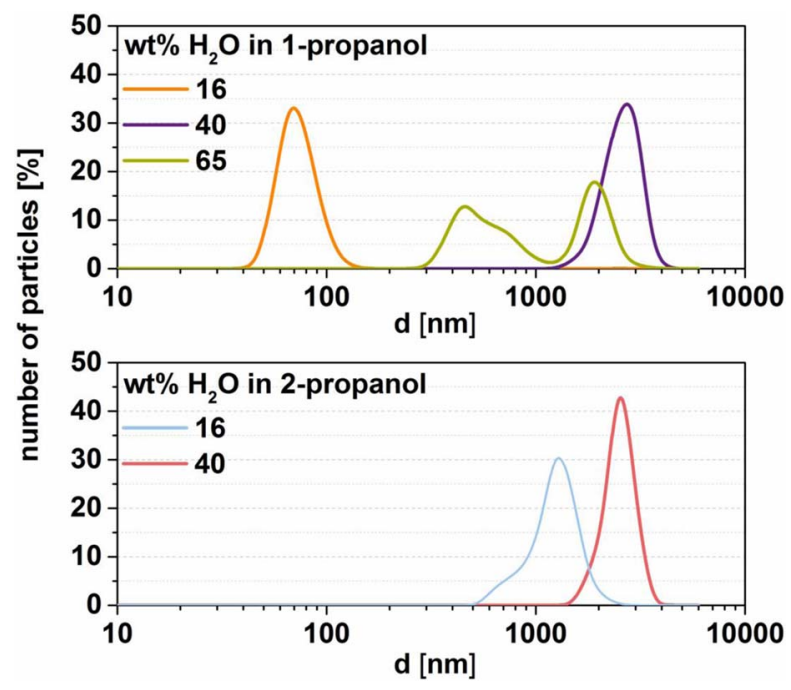

Figure 9. Distribution of the hydrodynamic diameter obtained by DLS measurements of $700 \mathrm{EW}$ ionomer solutions with different water content in either 1-propanol (upper panel) or 2-propanol (lower panel). The here used concentration of the ionomer is equivalent to that used in the catalyst inks (viz., $0.32 \mathrm{mg}_{\text {Ionomer }} / \mathrm{ml}_{\text {ink }}$ ). 


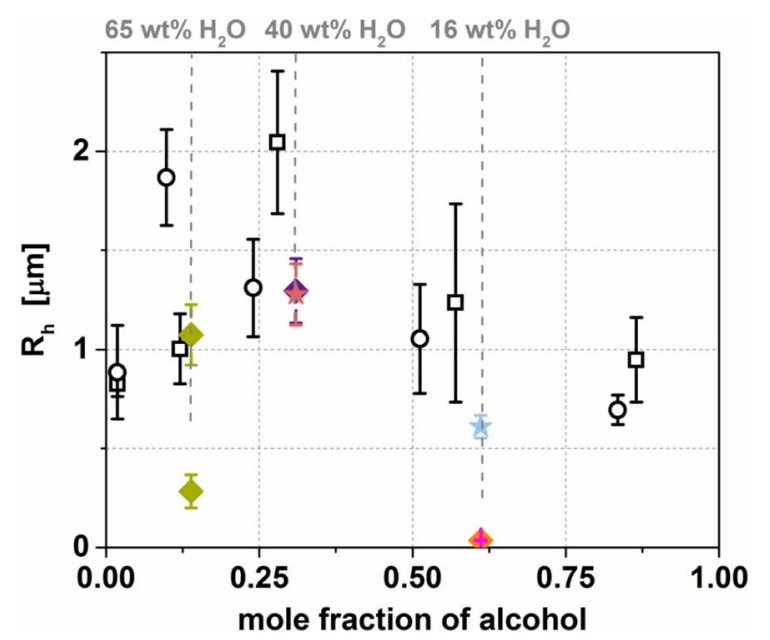

Figure 10. The hydrodynamic radii $\left(\mathrm{R}_{\mathrm{h}}\right)$ peak maxima of different ionomers with respect to the mole fraction of alcohol for the $700 \mathrm{EW}$ ionomer used in this study: 1-propanol/16 wt $\% \mathrm{H}_{2} \mathrm{O}$ (orange diamond), 1-propanol/40 wt $\% \mathrm{H}_{2} \mathrm{O}$ (purple diamond), 1-propanol/65 wt $\% \mathrm{H}_{2} \mathrm{O}$ (green diamonds), 2-propanol/16 wt $\% \mathrm{H}_{2} \mathrm{O}$ (light blue star), and 2-propanol/40 wt $\% \mathrm{H}_{2} \mathrm{O}$ (pink star). Each sample was measured five times to and the error bars show the standard deviation. The data from this study are compared with data on Nafion 1100 EW published by Yamaguchi et al., 15 who determined $R_{h}$ from self-diffusion coefficients obtained from DLS decay profiles in either water/1-propanol (open circles) or water ethanol (open squares). The water contents of 16, 40, and $65 \mathrm{wt} \%$ are given at the upper $\mathrm{x}$-axis and marked by dashed gray lines.

Changes of the hydrodynamic radii when increasing the mole fraction of alcohol in alcohol/water solutions with 1100 EW Nafion ionomer have already been observed for 2-propanol, 1-propanol, and ethanol based solutions by Yamaguchi et al., ${ }^{15}$ who used a similar ionomer concentration of $30 \mathrm{mg}_{\text {Ionomer }} / \mathrm{ml}_{\text {ink }}$. Unfortunately, they did not correlated their findings with MEA performance. Hydrodynamic radii in our study, particularly for the 1-propanol/16 wt $\% \mathrm{H}_{2} \mathrm{O}$ mixture, are somewhat smaller than the ones reported by Yamaguchi et al. ${ }^{15}$ Figure 10), despite the similar ionomer concentration. We attribute this difference to the different equivalent weight of the ionomer and/or the different side-chain chemistry. Interestingly the size of the secondary ionomer aggregates in the various ionomer/solvent mixtures is similar to the ionomer patches size observed in the catalyst layers (see Figure 7), suggesting that the here presented type of DLS analysis may be able to provide an estimate whether ionomer patches might be formed in catalysts layers.

\section{Conclusions}

The $50 \mathrm{~cm}^{2}$ single-cell $\mathrm{H}_{2}$ /air performance of cathodes prepared by a decal transfer process with inks composed of a $700 \mathrm{EW}$ ionomer in different mixtures of alcohols (1-propanol and 2-propanol) and water (16-65 wt $\%$ was correlated with the morphology of the cathode electrodes as well as with physical-chemical properties of the catalyst layers and the ionomer/solvent mixtures.

Scanning electron microscopy (SEM) analysis of the cathode electrodes revealed the formation of large ionomer patches at the electrode surface (i.e., the surface facing the diffusion medium) for inks with high water content, particularly when 2 propanol is used. As the fractional coverage of the electrode surfaces with ionomer patches increased, the $\mathrm{H}_{2}$ /air performance particularly under wet operating conditions, decreased dramatically. The hydrodynamic radii $\left(\mathrm{R}_{\mathrm{h}}\right)$ of the secondary aggregates of the $700 \mathrm{EW}$ ionomer was studied in concentrated ionomer solutions by dynamic light scattering (DLS), from which it was found that the size of the secondary aggregate was the smallest for the inks which yielded the best $\mathrm{H}_{2}$ /air performance under wet operating conditions and which had the smallest number and size of ionomer patches (inks based on 1-propanol with 16 wt $\% \mathrm{H}_{2} \mathrm{O}$ ).
$\mathrm{N}_{2}$-adsorption analysis using a QSDFT model showed that the blocking of micro and mesopores in catalyst layers is most pronounced for inks which are characterized by a small $R_{h}$ value and for electrodes for which only few and small ionomer patches can be observed.

An ink composition dependent ionomer distribution model is proposed, which allows to correlate the above described observations. It also explains why the proton resistivity of the cathode electrode determined by electrochemical impedance spectroscopy is not affected by the ink composition used for the preparation of the cathode electrodes, even though their $\mathrm{H}_{2}$ /air performance and their morphology differ dramatically.

\section{Acknowledgments}

This work was supported by Greenerity $\mathrm{GmbH}$ and the German Federal Ministry of Economy (BMWi; under the project support number 03ET2058C) within the HyMotion5 research collaboration. We thank Matthias Binder, Christian Eickes, Peter Suchsland, and Jozsef Speder from Greenerity GmbH for their valuable and critical discussion of the here presented results during the course of this project. The authors would also like to thank Martin Thomas from Quantachrome for the fruitful discussions and insights into the QSDFT kernels. The electron microscopy was conducted at the WACKER-Chair of Macromolecular Chemistry of the Technische Universität München with the expert assistance of Katia Rodewald. The DLS measurements were carried out at the BEC of the Munich University of Applied Science.

\section{ORCID}

Alin Orfanidi (1) https://orcid.org/0000-0001-8197-8059

Philipp J. Rheinländer (D) https://orcid.org/0000-0002-0018-065X

\section{References}

1. R. N. Bonifácio, J. O. A. Paschoal, M. Linardi, and R. Cuenca, J. Power Sources, 196, 4680 (2011).

2. M. Brodt, T. Han, N. Dale, E. Niangar, R. Wycisk, and P. Pintauro, J. Electrochem. Soc., 162, F84 (2015).

3. M. S. Saha, A. F. Gulla, R. J. Allen, and S. Mukerjee, Electrochim. Acta, 51, 4680 (2006).

4. J. M. Song, S. Suzuki, H. Uchida, and M. Watanabe, Langmuir, 22, 6422 (2006)

5. M. Lopez-Haro, L. Guétaz, T. Printemps, A. Morin, S. Escribano, P. H. Jouneau, P. Bayle-Guillemaud, F. Chandezon, and G. Gebel, Nat. Commun., 5, 5229 (2014).

6. M. Wilson and S. Gottesfeld, J. Appl Electrochem, 22, 1 (1992).

7. M. Wilson and S. Gottesfeld, J. Electrochem. Soc., 139, L28 (1992).

8. J. Shin, J. K. Lee, H. Y. Ha, S. A. Hong, H. S. Chun, and I. H. Oh, J. Power Sources, 106, 146 (2002).

9. M. Chisaka and H. Daiguji, Electrochimica Acta, 51, 4828 (2006).

10. Steven Holdcroft, Chem. Mater, 26, 381 (2014).

11. D. C. Huang, P. J. Yu, F. J. Liu, S. L. Huang, K. L. Hsueh, Y. C. Chen, C. H. Wu, W. C. Chang, and F. H. Tsau, Int. J. Electrochem. Sci., 6, 2551 (2011).

12. T. Kusano, T. Hiroi, K. Amemiya, M. Ando, T. Takahashi, and M. Shibayama, Polymer Journal, 47, 546 (2015).

13. C. Welch, A. Labouriau, R. Hjelm, B. Orler, C. Johnston, and Yu Seung Kim, ACS Macro Lett., 1, 1403 (2012)

14. T. Ngo, T. L. Yu, and H. L. Lin, J. Power Sources, 225, 293 (2013).

15. M. Yamaguchi, T. Matsunaga, K. Amemiya, A. Ohira, N. Hasegawa, K. Shinohara, M. Ando, and T. Yoshida, J. Phys. Chem. B, 118, 14922 (2014).

16. Y. S. Kim, C. F. Welch, R. P. Hjelm, N. H. Mack, A. Labouriau, and E. B. Orler, Macromolecules, 48, 2161 (2015).

17. O. Groeger, H. A. Gasteiger, and J. P. Suchsland, J. Electrochem. Soc., 162, A2605 (2015).

18. N. Konno, S. Mizuno, H. Nakaji, and Y. Ishikawa, SAE Int. J. Alt. Power. 4, 123, (2015).

19. K. E. Martin and J. P. Kopasz, Fuel Cells, 9, 356 (2009)

20. A. Kongkanand and M. F. Mathias, J. Phys. Chem. Lett., 7, 1127 (2016).

21. J. Peron, D. Edwards, M. Haldane, X. Luo, Y. Zhang, S. Holdcroft, and Z. Shi, J. Power Sources, 196, 179 (2011).

22. C. Lei, D. Bessarabov, S. Ye, Z. Xie, S. Holdcroft, and T. Navessin, J. Power Sources, 196, 6168 (2011).

23. Y. C. Park, K. Kakinuma, H. Uchida, M. Watanabe, and M. Uchida, J. Power Sources, 275, 384 (2015).

24. D. R. Baker, D. A. Caulk, K. C. Neyerlin, and M. W. Murphy, J. Electrochem. Soc., 156, B991 (2009).

25. A. Orfanidi, P. Madkikar, H. A. El-Sayed, G. S. Harzer, T. Kratky, and H. A. Gasteiger, J. Electrochem. Soc., 164, F418 (2017) 
26. Y. Liu, C. Ji, W. Gu, J. Jorne, and H. A. Gasteiger, J. Electrochem. Soc., 158, B614 (2011).

27. W. Gu, D. R. Baker, Y. Liu, and H. A. Gasteiger, in Handbook of Fuel Cells: Advances in Electrocatalysis, Materials, Diagnostics and Durability, (editors: W. Vielstich, H. A. Gasteiger, and H. Yokokawa), John Wiley \& Sons, UK Chichester, 2009, 631.

28. A. V. Neimark, Y. Lin, P. I. Ravikovitch, and M. Thommes, Carbon, 47, 1617 (2009).

29. G. Y. Gor, M. Thommes, K. A. Cychosz, and A. V. Neimark, Carbon, 50, 1583 (2012).

30. Johna Leddy, Book of Nanomaterials for Sustainable Energy, Chapter 6, pp. 99, ACS Symposium Series, Vol. 1213.

31. K. C. Neyerlin, W. Gu, J. Jorne, and H. A. Gasteiger, J. Electrochem. Soc., 153, A1955 (2006).

32. H. A. Gasteiger, S. S. Kocha, B. Sompalli, and F. T. Wagner, J. Appl. Catal. B, 56, 9 (2005).

33. F. T. Wagner, S. G. Yan, and P. T. Yu, Handbook of Fuel Cells - Fundamentals, Technology and Applications, (eds.: H. Yokokawa, H. A. Gasteiger, and W. Vielstich), John Wiley \& Sons Chichester, 5, 250 (2009).

34. Y. Liu, C. Ji, W. Gu, D. Baker, J. Jorne, and H. A. Gasteiger, J. Electrochem. Society, 157, B1154 (2010)

35. M. F. Mathias, R. Makharia, H. A. Gasteiger, J. J. Conley, T. J. Fuller, C. J. Gittleman, S. S. Kocha, D. P. Miller, C. K. Mittelsteadt, T. Xie, S. G. Yan, and P. T. Yu, The Electrochemical Society Interface, 14, 24 (2005).
36. T. Soboleva, X. Zhao, K. Malek, Z. Xie, T. Navessin, and S. Holdcroft, ACS Appl. Mater. Interfaces, 2, 375 (2010)

37. M. E. Hannach, T. Soboleva, K. Malek, A. A. Franco, M. Prat, J. Pauchet, and S. Holdcroft, J. Power Sources, 247, 322 (2014).

38. Y. C. Park, H. Tokiwa, K. Kakinuma, M. Watanabe, and M. Uchida, J. Power Sources, 315, 179 (2016).

39. M. Thommes, B. Smarsly, M. Groenewolt, P. I. Ravikovitch, and A. Neimark, Langmuir, 22, 756 (2006)

40. J. Landers, G. Y. Gor, and A. V. Neimark, Colloids Surf. A, 437, 3 (2013)

41. K. Kaneko and C. Ishii, Coll Surf, 67, 203 (1992).

42. A. M. Puziy, O. I. Poddubnaya, A. Martínez-Alonso, F. Suárez-García, and J. M. D. Tascón, Appl Surf Sci, 200, 196 (2002)

43. M. L. Occelli, J. P. Olivier, J. A. Perdigon-Melon, and A. Auroux, Langmuir, 18, 9816 (2002).

44. H. Shi, Electrochim Acta, 41, 1633 (1996).

45. Z. Wang, H. Tang, J. Li, Y. Zeng, L. Chen, and M. Pan, J. Power Sources, 256, 383 (2014).

46. T. T. Ngo, T. Leon Yu, and H. Lin, J. Power Sources, 238, 1 (2013)

47. S. J. Lee, T. L. Yu, H. L. Lin, W. H. Liu, and C. L. Lai, Polymer, 45, 2853 (2004).

48. P. A. Cirkel, T. Okada, and S. Kinugasa, Macromolecules 32, 531 (1999).

49. P. A. Cirkel and T. A. Okada, Macromolecules, 33, 4921 (2000).

50. W. H. Liu, T. Y. Yu, T. L. Yu, and H. L. Lin, Polym. 7, 1264 (2007). 